\title{
Biological Approaches for Sustainable Utilization of Aconitum: A Genus Containing Valuable Medicinal Properties
}

\section{Gaur $\mathrm{AK}^{1 *}$ and Sharma $\mathrm{E}^{1}$}

1Department of Molecular Biology and Genetic Engineering, G.B. Pant University of Agriculture and Technology, India

*Corresponding author: Anil Kumar Gaur, Department of Molecular Biology \& Genetic Engineering, G. B. Pant University of Agriculture and Technology, Pantnagar263 145, Uttarakhand, India, Email: anilgaur123@rediffmail.com

\section{Research Article \\ Volume 3 Issue 1}

Received Date: December 21, 2018

Published Date: February 13, 2019

DOI: $10.23880 /$ ggtij-16000110

\section{Abstract}

Aconitum genus (Ranunculaceae) is well recognized for medicinal worth. Diterpenoid alkaloids (aconitines) are integral part of Aconitum which make them commercially valuable. The species of Aconitum genus have very small populations in different pockets of the globe; which need effective strategies for its conservation as an important natural resource that's why; the production of aconitines through biotechnological means is desirable. In the present review an attempt has been made to throw some focus on possible biogenesis pathway of aconitines and biological approaches to understand it. Upscale production strategies of aconitine which are going on and still need to be done correlating to other medicinal plants have been discussed. Our own efforts are also covered regarding gene mining of possible rate limiting steps with special reference to Aconitum balfourii Stapf. The aim of the present review is to give emphasis on recent biotechnological approaches to be applied which are lacking in Aconitum, however, these approaches are often being utilized in other medicinal plants for their valuable usages.

Keywords: Aconitum; Biochemical Pathway; Diterpenoid Alkaloids; Elicitors

Abbreviations: IPP: Isopentyl Di Phosphate; DMAPP: Dimethylallyl Diphosphate; MEP: 2-C-Methyl-D-Erythritol 4-Phosphate; GPP: Geranyl Pyrophosphate; FPP: farnesyl pyrophosphate; GGPP: gerenyl gerenyl pyrophosphate.

\section{Introduction}

Medicinal plants have been drawn considerable attention because people all over the world need medicines that should be safe and intrinsically good for health. Therefore consumption of herbal medicines is widespread and increasing [1]. India is gifted with huge biodiversity. The plant extracts have been used to make the Ayurvedic formulations for curing several ailments since ancient time. Himalayan region of India is considered as one of the hot spot of biodiversity. Of huge biodiversity in the Himalaya, Aconitum belonging to family Ranunculaceae pay a major contribution to it. The 


\section{Genomics \& Gene Therapy International Journal}

pharmaceutically significant compound present in the roots of Aconitum is a type of diterpenoid alkaloid [2]. Several different types of diterpenoids alkaloids (Figure 1) are present in the plant which is highly toxic in nature. A long history of their use in several systems of medicines in India, China and Tibet is evidenced from ancient literature. The most common medicinal application of aconite preparations is the management of pain associated with rheumatism, arthritis, gout, neuralgia, sciatica, migraine and cancer. In homeopathy, aconite is used to dispel fear, anxiety and stress [3].

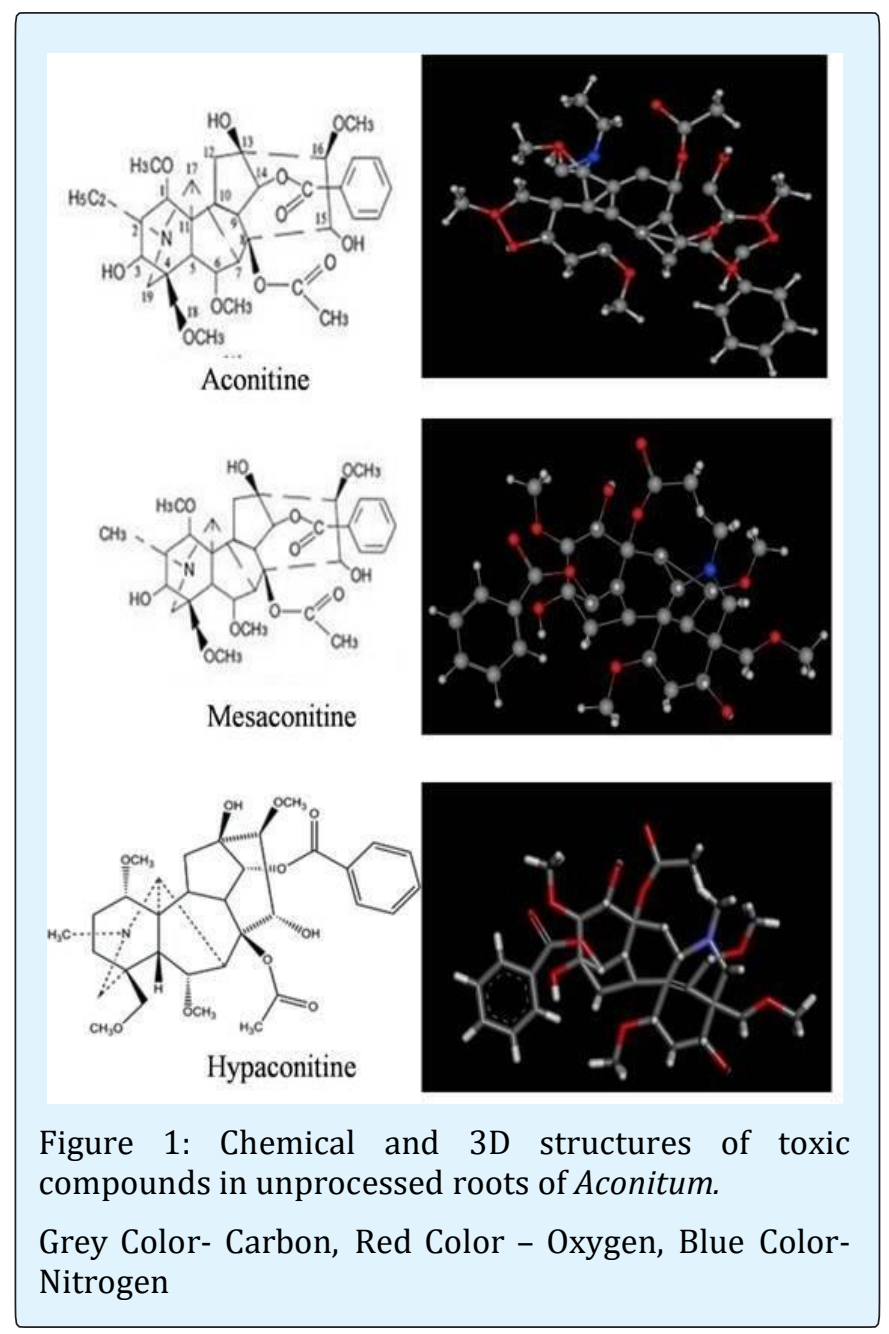

About 1358 species of this genus were reported all over the world (IPNI data). In the Himalayan regions it is distributed in Pakistan, India, Nepal, Bhutan and South Tibet, where aconites are used in local and traditional system of medicine [4]. A small group is also found in the
Western North America and Eastern United States of America. In India the genus is represented by 24 species and is known as Indian Aconites. Out of two dozen aconitum plant species thirteen possess drug value $[5,6]$ provided major contribution in the taxonomy of Indian aconites. He classified genus as existed in India and arranged the species in three sections on the basis of their root structures [7] (Table 1).

Aconitines are the ingredient of several medicines but the low content found in wild plants is a serious limitation towards its effective utilization. Aconites natural population is very low while aconitines demand is very high as compare to their population and there is no report of commercial cultivation of Aconitum from any area [8]. Hence, all the demand of pharmaceutical companies is being entirely met by wild collection only. It poses heavy strain on wild habitat and due to continuous overexploitation Aconitum genus faces severe threat and leads into endangered category $[9,10]$. In the view of current scenario, it is essential to take the genus into consideration for various biological approaches to enhance the production of aconitines in vitro as well as in vivo. Several aspects viz evolutionary, pharmacological, toxicological, isolation and characterization of diterpenoid alkaloids, their phytochemical properties and conservation through micro propagation of various species of Aconitum have been undertaken so far by the scientists all over the world [11-19]. However, there is a lack of studies related to rate limiting gene(s) mining and their molecular characterization, gene over expression studies, and metabolic pathways study with the help of precursors, inhibitors and elicitors both at national and international level. We are working on Aconitun balfourii Stapf. One of the valuable Indian aconite. The rare cultures which need very specific habitat conditions were established successfully in in vitro facilities. Now, we are focusing our research on above mentioned lacking areas. In the present review we will discuss about possible biogenesis of diterpenoid alkaloids and biological approaches to understand the complex secondary metabolism of aconites and efforts of enhancing secondary metabolites of commercial values. These all areas will be discussed in the review correlating to other medicinal plants with the intention that these mentioned approaches might also be applied in Aconitum. It will surely prove beneficial for enhancing and understanding towards aconitines biogenesis which is an ultimate commercial product [20]. 


\section{Genomics \& Gene Therapy International Journal}

\begin{tabular}{|c|c|c|c|c|c|c|}
\hline Species & Section & Subsection & Habitat & Altitude(m) & $\begin{array}{c}\text { Threat } \\
\text { Status }\end{array}$ & $\begin{array}{c}\text { Drug } \\
\text { value }\end{array}$ \\
\hline A.gymnandrumMaxim & Gymnaconitum & - & Tibetan plateau & $3000-4500$ & - & - \\
\hline A.laeve Royle & Lycoctonum & - & $\begin{array}{c}\text { Jammu \& Kashmir, Himanchal } \\
\text { Pradesh, uttaranchal }\end{array}$ & $3200-4200$ & - & - \\
\hline A.luridum Hook.f. \& Thomson & Lycoctonum & - & Eastern Nepal to Chambai & $3600-4200$ & - & Possess \\
\hline A.moschatum Stapf & Lycoctonum & - & Jammu \& Kashmir & - & - & \\
\hline A.soongaricum Stapf & Napellus & Napellus & Kashmir, Central Asiatic provience & - & - & - \\
\hline $\begin{array}{c}\text { A.chasmanthum Stapf ex } \\
\text { Holmes }\end{array}$ & Napellus & Napellus & $\begin{array}{c}\text { Western Himalaya from Chitral to } \\
\text { Hazara, Himanchal Pradesh }\end{array}$ & $2100-3600$ & - & Possess \\
\hline A. violaceum JACQ Ex Stapf & Napellus & Napellus & Kumaon Himalaya & $3000-4500$ & VL & Possess \\
\hline A.falconeri Stapf & Napellus & Napellus & $\begin{array}{c}\text { Alpine \& Subalpine zones of } \\
\text { Garhwal Himalaya }\end{array}$ & - & CE & Possess \\
\hline A. spicatum Stapf. & Napellus & Napellus & Sikkim Himalaya & - & VL & Possess \\
\hline A. laciniatum Stapf & Napellus & Napellus & Sikkim Himalaya & $3300-4200$ & & Possess \\
\hline A. ferox WALL. EX SERINGE & Napellus & Napellus & $\begin{array}{c}\text { Sikkim to Garhwal Himalaya, } \\
\text { Assam }\end{array}$ & - & CE & Possess \\
\hline A.heterophylloidsSta pf & Napellus & Napellus & - & - & - & - \\
\hline A.leucanthum Stapf. & Napellus & Napellus & Himalaya of Nepal to Bhutan, \\
SE tibet & $3600-4500$ & - & \\
\hline
\end{tabular}

Table 1: Indian Aconites and their distribution pattern.

\section{Bioactive Compound of Genus Aconitum}

Before discussing the proposed biogenesis of aconitine type diterpenoid alkaloids, we are giving a brief introduction of alkaloids (bioactive compounds) [21] stated that bioactive compounds in plants can be defined as secondary plant metabolites eliciting pharmacological or toxicological effects in man and animals. Bioactive compound of genus Aconitum are composed of several true and pseudoalkaloids collectively called as aconitines. Diterpenoid alkaloids fall into category of pseudoalkaloid and these were very well characterized by Rehman \& Choudhary [22]. Recently again 10 year's investigation (from 1998 to the end of 2008) on diterpenoid alkaloids was superbly compiled by Wang et al [15]. They covered more than 300 new diterpenoid alkaloids which have been isolated in ten years from different genera and focused on their structural relationships, and investigations into their chemical reactions, synthesis, and biological activities. They have classified diterpenoid as into three categories viz; C18, C19 and C20 type.

Diterpenoid alkaloids are derived in nature from tetracyclic or pentacyclic diterpenes in which carbon atoms 19 and 20 are linked with the nitrogen atom of a molecule of $\beta$-aminoethanol, ethylamine or methylamine to form a heterocyclic ring [23]. In the recent years it has been generally assumed that C20 and C19 skeleton of the alkaloids isolated from the plants of the Garraya, Aconitum and Delphinium species were terpenoids and as such produced, in vivo from acetate units by MVA pathway so well established for the biosynthesis of nonalkaloidal terpenes [24]. Thus these alkaloids are commonly referred as the diterpenoid alkaloids. The possible pathway by which nitrogen atom enters the skeleton remains obscure. It may be presumed that a di-aldehydic precursor accept an ammonia molecule from a glutamine or lysine residue, as appears to be the case for the triterpenoid steroidal alkaloids, in a reductive amination process [25]. In current years studies proved that serine amino acid is an important in the biosynthesis and donate nitrogen atom to complete the structure of diterpenoid alklaoids [26].

\section{Biogenesis of Diterpenoid Alkaloids}

Several secondary metabolites which are originated from terpenoid backbone are synthesized in plants through isoprenoid pathway. Isoprenoids are the most ancient and diverse class of natural products but they all originate through the condensation of the universal phosphorylated derivative of hemiterpene IPP (Isopentyl di phosphate) and dimethylallyl diphosphate (DMAPP). IPP is the central intermediate which is synthesized from two distinct routes, the classical mevalonate route which is effective in cytosol and recently discovered 2-Cmethyl-D-erythritol 4-phosphate (MEP) in plastids. These precursors are combined together to construct the higher order structures such as geranyl pyrophosphate (GPP), farnesyl pyrophosphate (FPP) and gerenyl gerenyl 


\section{Genomics \& Gene Therapy International Journal}

pyrophosphate (GGPP) $[27,28]$. It is generally accepted that the cytosolic pool of IPP serves as a precursor of sesquiterpenes, triterpenes, sterols and polyterpenes whereas the plastid pool of IPP provides the precursors of mono-, di- and tetraterpenes [29]. Some exceptions have been described showing that interactions between the two biosynthetic pathways may exist. There is a compartmentalization of precursor isoprene unit during the synthesis of terpenoids and both the pathways are contributed precursors for the synthesis of terpenoids. There is a sign of crosstalk of two pathways during terpenoid synthesis in plants [30].

IPP pool is the building blocks on which several complex reactions take place and many structurally complex intermediates compounds are formed to complete the different pseudoalkaloids structure. In the formation of IPP two routes are followed; in MEP, the initial step of the plastidic 2C-methyl-D-erythritol 4-phosphate (MEP) pathway that produces isopentenyl diphosphate is catalyzed by 1-deoxy-D-xylulose-5-phosphate synthase.
Estevez, et al. [31] proved with the help of transgenic Arabidopsis that this enzyme catalyzes one of the rate limiting steps in MEP pathway. In MVA pathway the initial steps involve the fusion of three molecules of acetyl-CoA to produce 3-hydroxy-3-methylglutaryl-CoA (HMG-CoA). The HMG-CoA is then reduced to yield mevalonic acid in a NADPH-dependent double reduction. This step is catalyzed by mevalonate: NADP oxido reductase, CoA acylating; 3-hydroxy-3-methylglutaryl coenzyme A reductase (HMGR; EC 1.1.1.34) [32]. However, the rate limiting nature of HMGR in plants and its regulation remain controversial [33,34]. Evidence for the contribution of HMGR as the rate limiting enzyme in isoprenoid biosynthesis has come from several investigators in which they have shown an induction in isoprenoid biosynthesis and a concomitant increase in HMGR activity [35-40]. DXS and HMGR are considered as rate limiting and the key players for synthesis of various isoprenoids in higher plants. Possible biogenesis of aconitines type of alkaloids is represented in Figure 2 [4145].

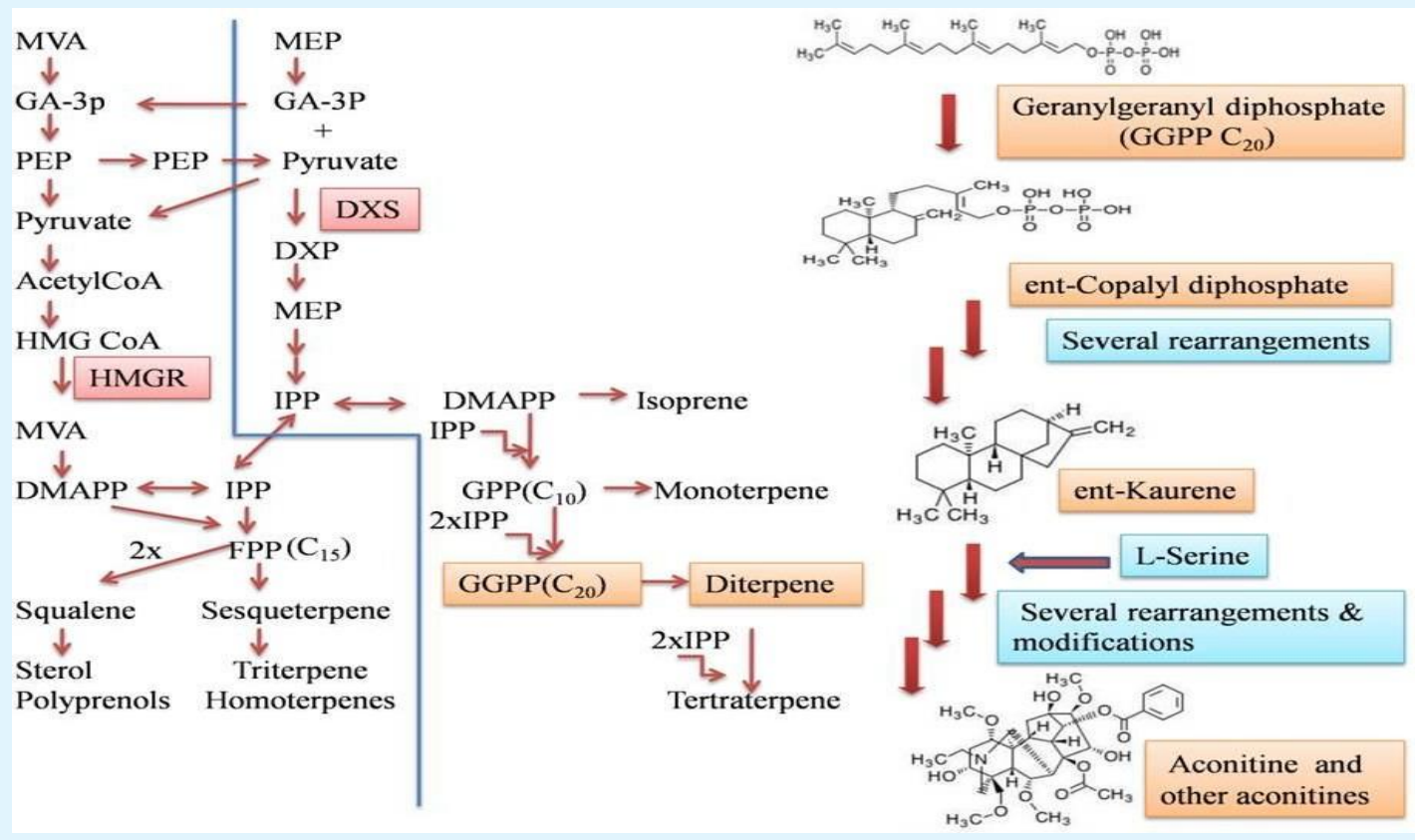

Figure 2: Possible biogenesis of aconitine type diterpenoid alkaloids.

IPP- Isopentyl diphosphate; DMAPP- Dimethylallyl di phosphate; MVA- Mevalonate pathway; MEP- 2-C- methyl-Derythritol 4-phosphate or non mevalonate pathway;HMGR- Hydroxymethyl glutaryl CoA reductase; DXP-1-Deoxy-Dxylulose-5-phosphate; DXS- 1-Deoxy-D-xylulose-5-phosphate synthase; DXR- 1-Deoxy-D- xylulose-5-phosphate reductoisomerase; GPP- Gerenyl diphosphate; GGPP- Gerenyl gerenyl diphosphate; FPP- Fernesyl diphosphate; GA-3PGlyceraldehyde 3 phosphate; PEP- Phosphoenol pyruvate.

(http://www.nature.com/nchembio/journal/v5/n5/fig_tab/nchembio.158_F3.html

http:/www.kegg.jp/keg-bin/highlight_pathway?scale=1.0\&map00904 \&keyword=aconitine) 


\section{Genomics \& Gene Therapy International Journal}

\section{Recent Approaches Concerning Pathway Identification and Upscale Production Still Going on Tissue Culture}

Plant cell culture technology is being used for commercial scale production of various secondary metabolites in which elicitation process has been effective at increasing the product yield. Hence challenging the cultures with elicitors facilitate to achieve a better understanding regarding pathway identification [46]. Elicitors could be used as enhancers of plant-secondarymetabolite synthesis and could play an important role in biosynthetic pathways to enhance production of commercially important compounds [47-50]. Methyl jasmonate and salicylic acids are two very common elicitors that have been used to study various plants species. Precursors and inhibitors studies are also proved beneficial to unravel the complex secondary metabolic pathways [51,52]. The studies related to this aspect on various medicinal plants are summarized in which is one of the missing areas of research on Aconitum. However a minor effort was made by us to see the effect of early step terpenoid pathway precursors and inhibitors on aconitine accumulation and effect on probable key enzymeactivities

1-deoxy-D-xylulose phosphate synthase (DXS) and 3Hydroxy- 3-methyl glutaryl Coenzyme A reductase (HMGR). It was concluded that there is possibility of crosstalk between mevalonate and non mevalonate pathways during isopentyl pyrophosphate (IPP) supply for aconitine biosynthesis. However, it seems that the mevalonate pathway plays a greater role IPP synthesis [53].

Several efforts have been carried out so far on conservation aspects, of Aconitum species through micro propagation to save it from extinction. It is very necessary to optimize the micro propagation protocol for mass multiplication and generation of material for research purpose for high altitude plants such as A. balfourii Stapf. Therefore, in vitro propagation protocols were optimized [54]. Study of population genetic diversity is another method that provides useful information for biological conservation. Four populations of A. balfourii Stapf were studied through polypeptide pattern and isoenzyme markers to locate the genetic diversity. They studied three enzyme systems such as: esterase, superoxide dismutase, and catalase. On the basis of isoenzyme variations and banding pattern, they have identified seven polymorphic loci in four populations.

Some efforts have been reported on Aconitum species in which hydroponics and suspension culture were tried in following mention studies. Hydroponics (from the Greek words hydro water and ponos labor) is a method of growing plants using mineral nutrient solutions, in water, without soil. For more than a decade research groups have been working on the development of a new biotechnological method for the industrial production of secondary metabolites using whole plants cultivated in soilless conditions. Such a technology may require not only agronomical knowledge but also know-how developed for in vitro and bioreactor processes [55,56]. In Aconitum balfourii Stapf an attempt has been made to increase the aconitine content through hydroponics. The plants regenerated from tissue culture were cultivated by Pathak et al hydroponically with a hydroponics apparatus placed in green house containing continuously running Hoagland's solution. The plants cultivated hydroponically (after 27 days) got stronger and longer roots $(4.8 \pm 0.5)$ in comparison to plants regenerated from tissue culture (root length $2.7 \pm 1.0$ ). The hydroponically cultivated plants have greater dry weight of roots $(0.05 \mathrm{~g} / \mathrm{root})$ than tissue culture derived plants $(0.032 \mathrm{~g} /$ root $)$. Aconitine content was checked through HPLC and it was found that the maximum percentage of aconitine $0.024 \%$ in hydroponics cultivated plants as compared to plants collected from wild (Tungnath) $0.015 \%$ and tissue culture derived plants $0.0123 \%$. There is only single report on Aconitum suspension culture till date. In this study they have optimized the aconitine production in cell suspension culture of A. napellus. They investigated the effect of culture conditions on cell biomass and aconitine content. They have also observed the effect of salicylic acid and yeast extract on accumulation of aconitine. The results showed that proper culture conditions enhanced the content 2.5-3 folds as compared to control [57] (Table 2).

\begin{tabular}{|c|c|c|c|c|}
\hline Plant Source & Secondary metabolites & Culture type & Elicitor/Precursor & References \\
\hline Gossypiym barbadens & Gossypol & Hairy roots & SA,MJ & Frankfater, et al., 2009 \\
\hline Salvia miltiorhiza & Tashinone & Hairy root & SL, YE & Wu and Shi, 2008 \\
\hline Salvia miltiorrhiza & Tashinone & Hairy root & ABA & Ge and Wu, 2005 \\
\hline Salvia officinalis & Carsonic acid & Shoot cultures & MJ & Gao, et al., 2011 \\
\hline Euphorbia pekiensis & Isoeuphekinesis & Suspension & FE & Grzegorczyk, 2009 \\
\hline
\end{tabular}

Gaur AK and Sharma E. Biological Approaches for Sustainable Utilization of Aconitum: A Genus Containing Valuable Medicinal Properties. Genom \& Gene Ther Int J 2019, 3(1): 000110. 


\section{Genomics \& Gene Therapy International Journal}

\begin{tabular}{|c|c|c|c|c|}
\hline Linum album & Podophyllotoxin & Suspension & YE & Ardakani et al, 2005 \\
\hline Hypercium perforatum & $\begin{array}{c}\text { Phenylpropanoid } \\
\text { naphthodianthrons }\end{array}$ & Suspension culture & JA & Godzovska, et al., 2007 \\
\hline E. californica & Benzophenenthridine & Suspension & MJ+SA+YE & Cho, et al., 2008 \\
\hline Portulaca oleracea & Noradrelin & Suspension culture & MJ,SA & Piran and Piri, 2012 \\
\hline Ginkgo biloba & Bilobalide & Suspension culture & GPP,GGPP,IPP, DMAPP,FPP & Kang, et al., 2006 \\
\hline Angelica gigas & Decursin, decursinol & Root cultures & YE,MJ,SA,PA & Rhee, et al., 2010 \\
\hline Cistanche deseriticola & $\begin{array}{c}\text { Phenylthanoloid } \\
\text { glycosides }\end{array}$ & Suspension & PA,TYR,SA & Ouyang, et al. 2005 \\
\hline Pureria tuberose & Isoflavanoid & Suspension & YE,MJ,SA & Goyal and Ramawat,2008 \\
\hline Rauvolfia tetraphylla & Reserpine & Suspension & PGR & Anitha and Ranjitha, 2007 \\
\hline Vitis vinifera & Anthocyanin & Suspension & SA & Saw, et al., 2010 \\
\hline Silybum marianum & Silymarin & Hairy root & PA & Rahimi, et al.,2011 \\
\hline Datura metel L. & Hyosysamine & Root culture & BE,AE & Ajungla, et al., 2009 \\
\hline Salvia miltiorrhiza & Tanshinone & Suspension & BE, AE & Zhao, et al., 2010 \\
\hline
\end{tabular}

Table 2: Elicitors and precursors studies on medicinal plants.

SA: Salicylic acid; MJ: Methyl Jasmonate; SL: Sorbitol; YE: Yeast Extract; JA: Jasmonic acid; PA: Phenyl Alanine; ABA: $\beta$ aminobutyric acid; FE: Fungal Elicitor; TYR: Tyrosine; PGR: Plant Growth Regulator; BE: Biotic Elicitor; AE: Abiotic Elicitor.

\section{Root Cultures}

Hairy root culture exemplifies a potential biotechnological tool to enhance secondary metabolite production in several medicinal plants. Root culture established by transformation with Agrobacterium rhizogenes is regarded as advantageous resource of useful compounds because of the rapid growth in culture media without phytohormones and relatively high productivity of secondary metabolites compared to undifferentiated calli or cell suspension, or in some case roots of mother plants. It is an emerging tool to enhance the pharmacologically active compound and have been tried in lots of medicinal plants. Giri, et al. [58] was reported hairy roots production in Aconitum heterophyllum Wall. They successfully transformed embryonic cell culture of Aconitum heterophyllum Wall. By using A. rhizogenes strains viz. LBA 9402, LBA 9360, AND A4 for the induction of hairy roots. It was found that total alkaloid (aconite) content of transformed roots was $2.96 \%$, which was 3.75 times higher compared to $0.79 \%$ in the non-transformed roots. Agrobacterium rhizogene mediated transformation method has been used to enhance the secondary metabolites in several other plant species [59-62].

\section{Gene Mining and Functional Characterization}

We have previously illustrated the role of mevalonate and non mevalonate pathways in proposed biogenesis of aconitine type alkaloids. Therefore, the gene mining and their functional characterization of rate limiting steps of concerning pathways are very necessary $[63,64]$. It is supposed to be providing several clues for targeting genetic manipulation for upscale production of medicinally significant components in vitro as well as in vivo. Several studies have been carried out so far on isolation and characterization of rate limiting genes in several other medicinal plants. The discoveries are summarized in Table 3 . These types of studies are also needed in case of Aconitum genus. Therefore, an attempt has been successfully made in our laboratory to partially isolate and functionally characterized both rate limiting genes i.e. HMGR and DXS from A. balfourii Stapf. (Accession nos are KC425323.1 and KC514134.1 respectively). Bioinformatics analysis was carried out and the phylogenetic relationship (N-J method) of genes from other plants genes retrieved from database is shown in Figures 3 \& 4. To investigate the expression of HMGR and DXS in different tissues, total RNA was isolated from leaves, shoots and roots and subjected to RT-PCR and Real time

PCR analysis [65-69]. The result of RT- PCR and real time PCR were almost parallel to each other [70-73]. Expression profiling of AbDXS with reverse transcriptase PCR indicated constitutive expression in all tissues i.e. leaf, shoot and roots, however, differential expression patterns were obtained [74-77] (Figure5). 


\section{Genomics \& Gene Therapy International Journal}

\begin{tabular}{|c|c|c|c|c|}
\hline Plant source & Gene & Substrate binding motif/ & NADPH/TPP binding motif & References \\
\hline Nicotiana sylvestris & HMGR & EMPIGYVQIP & DAMGMNM & Genschik, et al.,1992 \\
\hline Camptotheca acuminate & HMGR & EMPVGYVQIP & DAMGMNM & Maldonado, et al.,1997 \\
\hline Ustilago maydis & HMGR & EMPVGYVQIP & DAMGMNM & Croxen, et al., 1994 \\
\hline Gossypium hirsutum L. & HMGR & EMPVGYVQIP & DAMGMNM & Loguercio, et al.,1999 \\
\hline Morus alba & HMGR & EMPVGYVQIP & DAMGMNM & Jain, et al.,2000 \\
\hline Taxus medica & HMGR & EMPVGYVQIP & DAMGMNM & Liao, et al.,2004 \\
\hline Eucomia ulmoides & HMGR & EMPIGFLQIP & DAMGMNM & Jiang, et al.,2006 \\
\hline Ginkgo biloba & HMGR & EMPVGVVQIP & GTVGGGT & Shen, et al., 006 \\
\hline Corylus avellana & HMGR & EMPIGFLQIP & DAMGMNM & Wang, et al.,2007 \\
\hline Solanum nigrum & HMGR & EMPVGYVQLP & - & Jose, et al.,2008 \\
\hline Salvia miltiorrhiza & HMGR & EMPVGYVQIP & DAMGMNM & Liao, et al.,2009 \\
\hline Jatropha curcas & HMGR & EMPIGFLQIP & DAMGMNM & Lin, et al., 2009 \\
\hline Euphorbia pekinensis & HMGR & EMPVGYVQIP & DAMGMNM & Cao, et al., 2010 \\
\hline Michelia chapensis & HMGR & EMPVGYVQIP & DAMGMNM & Cao, et al.,2011 \\
\hline Panax geneseng & HMGR & EMPVGYVQIP & DAMGMNM & Wu, et al, 2012 \\
\hline Catharanthus roseus & HMGR & EMPVGYVQLP & DAMGMNM & Abdin, et al., 2012 \\
\hline T. brevicorniculatum & HMGR & EMPVGYVQIP & DAMGMNM & Deenen, et al., 2012 \\
\hline Arabidopsis & DXR & LPADSEHSAI & GSTGSIGT & Paulet, et al., 2002 \\
\hline Ginkgo biloba & DXS & PSD, DRAG & LNDN, GDG & Gong, et al.,2006 \\
\hline Glycine max(Soybean) & DXS & PSD, DRAG & LNDN, GDG & Zhang, et al.,2009 \\
\hline Salvia Miltiorrhiza & DXR & LPADSEHSAI & GSTGSIGT & Wu, et al., 2009 \\
\hline Amomum villosum & DXS & PSD, DRAG & LNDN, GDG & Yang, et al., 2012 \\
\hline Amomum villosum & DXR & LPADSEHSAI & GSTGSIGT & Yang, et al., 2012 \\
\hline
\end{tabular}

Table 3: Cloning and characterization of rate limiting genes of isoprenoid pathway.

HMGR: 3-hydroxy-3-methyl glutaryl CoA reductase; DXS- 1-deoxy-D-xylulose-5-phosphate synthase, DXR-1- deoxy-Dxylulose-5-phosphate reductoisomerase

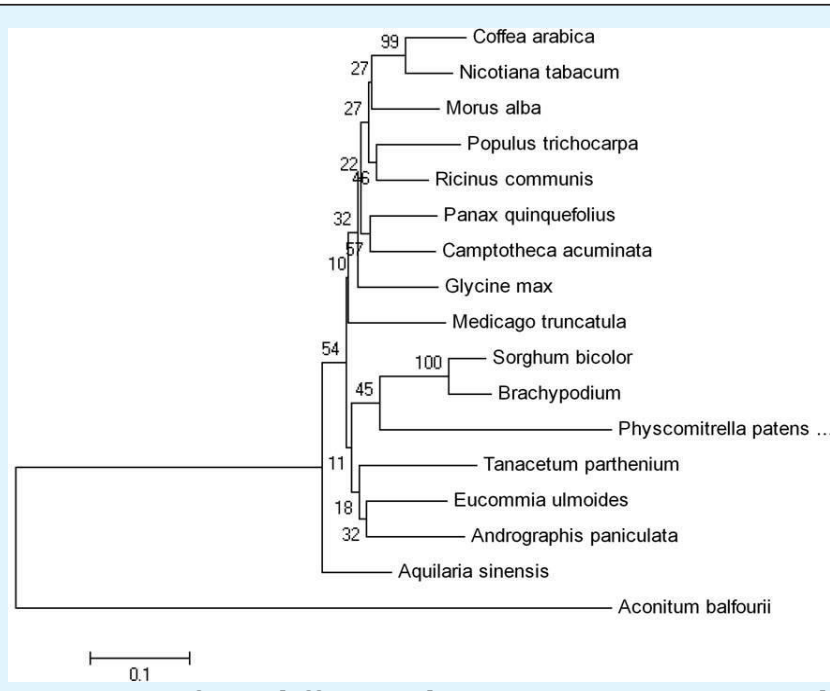

Figure 3: Phylogenetic tree of HMGR protein from different plant species. Sequence analysis was performed using Clustal $\mathrm{X}$, and the nearest neighbor-joining method was applied to create trees. Aconitum balfourii HMGR and related proteins Coffee arabica (ADR51242.1), Nicotiana tabacum (AAB87727.1), Morus alba(AAD03789.1), Populus trichocarpa (XP 002317026.1), Ricinus communis (XP 002510732.1), Panax quinquefolius (ACV65036.1), Camptotheca acuminata (AAB69726.1), Glycine max(XP 003519474.1), Medicago truncatula (XP 003629056.1), Sorghum bicolor (XP 002445887.1), Brachypodium (XP 003572378.1), Physcomitrella patens (XP 001771547.1), Tanacetum parthenium (AER00469.1), Eucommia ulmoides (AAV54051.1),Andrographis paniculata (AAP14352.2), Aquilaria_sinensis (AFU75319.1), 


\section{Genomics \& Gene Therapy International Journal}

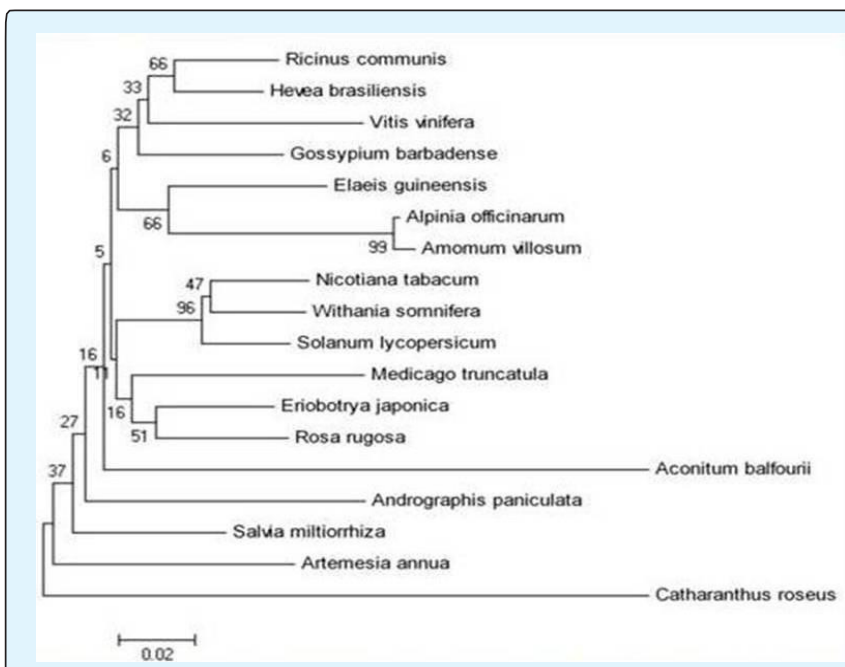

Figure 4: Phylogenetic tree of DXS proteins from different plant species. Sequence analysis was performed using Clustal $\mathrm{X}$, and the nearest neighborjoining method was applied to create trees. Aconitum balfourii DXS and related proteins from Ricinus communis (RcDXS, XP002516843.1), Hevea brasiliensis (HbDXS, BAF98288.1), Nicotiana tabacum (NtDXS, CAC17468.1), Andrographis paniculata (ApDXS, AAP14353.1), Salvia miltiorrhiza (SvDXS, ACF21004.1), Vitis vinifera (VvDXS, XP002277919.1), Elaeis guineensis (EgDXS, AAS99588.1), Eriobotrya japonica (EbDXS, AFP65821.1), Alpinia officinarum (AoDXS, AEK69518.1), Rosa rugosa (RrDXS, AEZ53173.1), Amomum villosum (AvDXS, ACR02668.1), Medicago truncatula (MtDXS, XP003609568.1), Solanum lycopersicum (SIDXS, NP001234672.1), Gossypium barbadense (GbDXS, ABN13970.1), Artemisia annua (AaDXS, AAD56390.2), Withania somnifera (WsDXS, AFI98878.1), Catharanthus roseus (CrDXS, ABI35993.1).

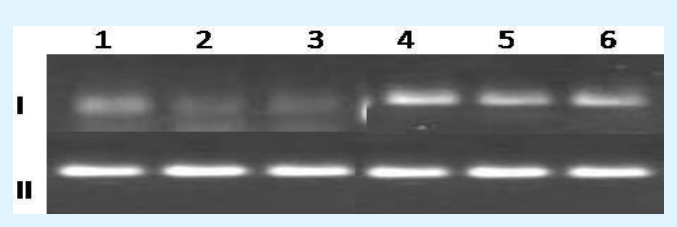

Figure 5: Expression pattern of HMGR and DXS in different $A$. balfourii tissues. Total RNA isolated from leaves, roots and stems, respectively, was subjected to one-step RT-PCR amplification (upper panel I). Actin gene was used as the control to show the normalization of the templates in PCR reactions (lower panel II).

In Upper panel: Lane 1, 2,3 -Expression of HMGR gene in leaf, stem and root tissues Lane 4, 5, 6- Expression of DXS gene in leaf, stem and root tissues

\section{Gene Over Expression}

Gene over expression analysis is also being successfully used to find out the correlation studies between related key gene(s) transcript level and secondary metabolite accumulation in several plant species $[77,78]$. Studies were carried out over expression studies in which HMG-Co A reductase gene (hmgr) from Catharanthus roseus (L) G. Don and amorpha-4, 11-diene synthase (ads) gene from A. annua L. were over-expressed in A. annua L. plants to study their effects on artemisinin yields [79-83]. The expressions of hmgr and ads at the transcriptional level were also confirmed in each transgenic line employing RT-PCR assays [84]. The HPLC analyses showed that the artemisinin contents were significantly increased in these transgenics. One of the transgenic lines, TR4, was found to contain 7.65-fold higher $(1.73 \mathrm{mg} / \mathrm{gDW})$ artemisinin than the nontransgenic plant (W) [85]. The increased artemisinin levels were found to be correlated with HMG-Co A reductase and amorpha- 4, 11-diene synthase enzymatic activities in the biochemical analyses [86,87]. Singh, et al. [88] studied the expression analysis of isoprenoid pathway in the presence of two inhibitors mevinolin and fosmidomycin in suspension cultures of Arnebia euchroma .They have suggested a positive correlation between shikonins content and expression of 3-hydroxy-3-methylglutarylCoAreductase (AeHMGR) and AePGT suggesting critical role played by thesegenes in shikonins biosynthesis [89].

\section{Conclusion and Future Perspectives}

In last few decades efforts have been made by scientist all over the world to understand plant secondary metabolism and its regulation. The marginal success in this field is due to structural complexity and tedious regulatory mechanism of secondary metabolic pathways .It is still a long way to go how these compounds are synthesized in plants and how their biosynthesis is regulated. Diterpenoid alkaloids (aconitines) are integral part of genus Aconitum which make it commercially valuable. However, the current knowledge regarding the biogenesis of aconitines is very limited; exemplify the major hurdle for successful metabolic engineering and commercialization. So, it is an essential requirement to consider the genus Aconitum for optimization of recent genetic engineering techniques which are being employ successfully in other medicinal plants. The different approaches involved in understanding biogenesis might be helpful for getting higher aconitines yield and saving the genus from extinction as well. 


\section{Genomics \& Gene Therapy International Journal}

\section{References}

1. Vines G (2004) Herbal harvest with a future: towards sustainable sources for medicinal plants. Plant life international.

2. Sultankhodzhaev MN, Nishnov AA (1995) Proposed biogenesis of diterpenoid alkaloid. Chemistry of Natural Compounds 31(3): 283-298.

3. Flemming $\mathrm{T}$ (2007) PDR for herbal medicines (Thompson health care).

4. The International Plant Names Index (2012) Published on the Internet.

5. Shah NC (2005) Conservation aspect of Aconitum species in the Himalayas with special reference to Uttaranchal. Med Plant Consev 11: 9-15.

6. Chakravarty HL, Chakravarti D (1954) Indian aconites. Eco. Bot. Botanical Garden Press, New York 8: 366-376.

7. Chaudhary LB, Rao RR (1998) Notes on the genus Aconitum L. (Ranunculaceae) in north-west Himalaya (India). Fed Rep 109(7-8): 527-537.

8. Stapf O (1905) The Aconites of India: A monograph. Ann Roy Bot Gard, Calcutta 10: 115.

9. Anonymous (2003) Wealth of India: Raw material (suppl.). Publication and Information Directorate, CSIR, New Delhi 1: 59.

10. Nautiyal BP, Vinay P, Bahuguna R, Maithani UC, Bisht $\mathrm{H}$, et al. (2002) Population study for monitoring the status of rarity of three Aconite species in Garhwal Himalaya. Trop Ecol 43(2): 297-303.

11. Kita Y, Ito M (2000) Nuclear ribosomal ITS sequences and phylogeny in East Asian Aconitum subgenus Aconitum (Ranunculaceae), with special reference to extensive polymorphism in individual plants. Plant Syst Evol 225(1-4): 1-13.

12. Luo Y, Zhang F, Yang Q (2005) Phylogeny of Aconitum subgenus Aconitum (Ranunculaceae) inferred from ITS sequences Plant Syst Evol 252(1-2): 11-25.

13. Mitka J, Sutkowska A, Ilnicki T, Joachimiak J (2007) Reticulate evolution of high alpine aconitum (Ranunculaceae) in the Eastern Sudetes and Western
Carpathians (Central Euorope). Acta Biol Cacoviensia Ser Bot 49(2): 15-26.

14. Ameri A (1998) The effect of Aconitum alkaloids on the central nervous system. Prog Neurobiol 56(2): 211-235.

15. Wang FP, Chen QH, Liu XY (2010) Diterpenoid alkaloids. Nat Prod Rep 27(4): 529-570.

16. Gao LM, Wei XM, Yang L (2005) Two new norditerpenoid alkaloids from Aconitum spicatum Stapf. Chin Chem Lett 16: 475-478.

17. Tang Q, Yang C, Ye W, Liu J, Zhao S (2007) Preparative isolation and purification of bioactive constituents from aconitum coreanum by high speed counter current chromatography coupled with evaporative light screening detection. J Chromatography 1144(2): 203-207.

18. Lyu HN, Kwak HY, Lee DY, Kim KT, Kim SY, et al. (2008) Isolation of flavanoids from processed aconite tubers. J Appl Biol Chem 51: 165.

19. Ahmad M, Ahmad WM, Zeeshan M, Obaidullah, Shaheen F (2008) Norditerpenoid alkaloid from the roots of Aconitum heterophyllum Wall with antibacterial activity. J Enzyme Inhib Med Chem 23(6): 1018-1022.

20. Sharma E, Gaur AK (2012) Aconitum balfourii Stapf: A rare medicinal herb from Himalayan Alpine. Journal of Medicinal Plant research 6(22): 3810-3817.

21. Bernhoft A (2010) A brief review on bioactive compounds in plants. Oslo (The Norwegian Academy of Science and Letters).

22. Rahman A, Choudhary MI (1999) Diterpenoid and steroidal alkaloids. Nat Prod Rep 16(5): 619-635.

23. Pelletier SW (1964) The chemistry of certain imines related to the diterpene alkaloids. Cellular and Molecular life sciences Experentia 20(1): 1-10.

24. Whalley WB (1962) Plausible schemes for the biosynthesis of the diterpenoid alkaloid skeleton. Tetrehedron 18: 43.

25. Kaneko H, Naruto S (1975) Constituents of Corydalis species. VIII. Constituents of Corydalis pallid var. tenuis, Yakugaku Zasshi 94: 01. 


\section{Genomics \& Gene Therapy International Journal}

26. Cherney EC, Baran PS (2011) Terpenoid-Alkaloids: Their biosynthetic twist of fate and total synthesis. Isr J Chem 51(3-4): 391-405.

27. McGarvey DJ, Croteau R (1995) Terpenoid metabolism. Plant Cell 7(7): 1015-1026.

28. Lange BM, Rujan T, Martin W, Croteau R (2000) Isoprenoid biosynthesis: The evolution of two ancient and distinct pathways across genomes. Proc Natl Acd Sci 97(24): 13172-13177.

29. Bhlomann J, Meyer G, Croteau R (1998) Plant terpenoid synthase: molecular biology and phylogenetic analysis. Proc Natt Acad Sci 95(8): 4126-4133.

30. Dudareva N, Anderson S, Orlova I, Gatto N, Ruchelt M, et al. (2005) The nonmevalonate pathway supports both monoterpene and sesquiterpene formation in Snapdragon flower. Proc Natt Acad Sci 102(3): 933938.

31. Estevez MJ, Cantero A, Reindl A, Reichler S, Leon P (2001) 1-deoxy- D -xylulose-5- phosphate synthase, a limiting enzyme for plastidic isoprenoid biosynthesis in plants. The Journal of Biological Chemistry 276(25): 22901-22909.

32. Rogers DH, Panini SR, Rudney H (1983) Properties of HMGCoA reductase and its mechanism of action, CRC Press, Inc., Boca Raton, pp: 57.

33. Chappel J (1995) Biochemistry and molecular biology of the isoprenoid biosynthesis pathway in plants. Annu Rev Plant Physio Plant Mol 46:521-547.

34. Stermer BA, Bianchini GM, Korth KL (1994) Regulation of HMG-CoA reductase activity in plants. J Lipid Res 35(7): 1133-1140.

35. Narita JO, Gruissem W (1989) Tomato hydroxymethylglutaryl-CoA reductase is required early in fruit development but not during ripening. Plant Cell 1(2): 181-190.

36. Frankfater CR, Dowd MK, Triplett BA (2009) Effect of elicitors on the production of gossypol and methylated gossypol in cotton hairy roots Plant Cell Tiss Organ Cult 98(3): 341-349.

37. Wu JY, Shi M (2008) Ultrahigh diterpenoid tanshinone production through repeated osmotic stress and elicitor stimulation in fed-batch culture of
Salvia miltiorrhiza hairy roots. Appl Microbiol Biotechnol 78(3): 441-448.

38. Ge X, Wu J (2005) Induction and potentiation of diterpenoid tashinone accumulation in Salvia miltiorrhiza hairy roots by $\beta$-aminobutyric acid. Appl Microbiol Biotechnol 68(2): 183-188.

39. Grzegorczyk I, Wysokinska H (2009) The effect of methyl jasmonate on production of antioxidant compounds in shoot cultures of Salvia officinalis L. Herba polonica 55(3): 238-243.

40. Gao FK, Yong YH, Dai CC (2011) Effect of endophytic fungal elicitor on two kinds of terpenoids production and physiological indexes in Euphorbia pekinensis suspension cells. J Med Plant Res 5(18): 4418-4425.

41. Ardakani SM, Hemmati S, Mohagheghzadeh A (2005) Effect of elicitors on the enhancement of podophyllotoxin biosynthesis in suspension culture of Linum album. DARU 13(2): 56-60.

42. Godzovska S, Maury S, Delaunay A, Spasenoski M, Joseph C, et al. (2007) Jasmonic acid elicitation of Hypercium perforatum L. cell suspensions and effect on the production of phenyl [ropanoids and naphtodianthrones, Plant cell Tiss Organ Cult 89: 113.

43. Cho HY, Son SY, Rhee HS, Yoon SY, Parson CWT, et al. (2008) Synergistic effect of sequential treatment with methyl jasmonate, salicylic acid and Yeast extract on benzophenanthridine alkaloid accumulation and protein expression in Escholtzia californica suspension cultures. J Biotech 135(1): 117-122.

44. Pirian K, Khosro P (2012) Effect of methyl jasmonate and salicylic acid on noradrelin accumulation in hairy roots of Portulaca oleracea L. International Res J Appl Basic Sci 3(1): 213-218.

45. Kang SM, Min JY, Kim YD, Park DJ, Jung HN, et al. (2006) Effect of supplementing terpenoid precursors on the accumulation of bilobalide and ginkgolides in Ginkgo biloba cell cultures. J Biotechnol123(1): 85-92.

46. Rhee HS, Cho HY, Son SY, Yoon SYH, Park JM (2010) Enhanced accumulation of decursin and decursinol angelate in root cultures and intact roots of Angelica gigas Nakai following elicitation. Plant Cell Tiss Organ Cult 101(3): 295-302. 


\section{Genomics \& Gene Therapy International Journal}

47. Ouyang J, Wang XD, Zhao B, Wang YC (2005) Enhanced production of phenylethanoid glycosides by precursor feeding to cell culture of Cistanche deseriticola. Process Biochemistry 40(11): 3480-3484.

48. Goyal S, Ramawat KG (2008) Increased isoflavanoids accumulation in cell suspension culture of Pureria tuberosa by elicitors. Indian J Biotech 7: 378-382.

49. Anitha S, Ranjitha Kumari BD (2007) Influence of auxin combinations on accumulation of reserpine in the callus of Rauvolfia tetraphylla L. Pakistan J Biological Sci 10(21): 3900-3904.

50. Saw NM, Riedel H, Kutuk O, Ravichandran K, Smetanska I (2010) Effect of elicitors and precursors on the synthesis of Anthocyanin in Grape Vitis vinifera cell cultures. Energy Res Journal 1(2):189192.

51. Rahimi S, Hasanloo T, Najafi F, Nejad RAK (2011) Enhancement of silymarin accumulation using precursor feeding in Silybum marianum hairy roots cultures. Plant Omics Journal 4(1): 34-39.

52. Ajungla L, Patil PP, Barmukh RB, Nikam TD (2009) Influence of biotic and abiotic elicitors on accumulation of hyoscyamine and scopolamine in root cultures of Datura metel L. IJB 8: 317-322.

53. Zhao JL, Zhou LG, Wu JY (2010) Effect of biotic and abiotic elicitors on cell growth and tanshinone accumulation in Salvia miltiorrhiza cell cultures. Appl Microbiol \& Biotechnol 87(1): 137-144.

54. Sharma E, Goel A, Gaur AK (2014) Effect of precursors and inhibitors on aconitine accumulation in in vitro root cultures of Aconitum balfourii Stapf. Ind J plant physiol 19(4): 375-381.

55. Pandey H, Nandi SK, Kumar A, Palni UT, Chandra B, et al. (2004) In vitro propagation of Aconitum balfourii Stapf; an important aconite of Himalayan alpine. J Hortic Sci Biotechnol 79(1): 34-41.

56. Zeng Y, Guo LP, Huang LQ, Sun YZ (2007) Plant hydroponics and its application prospect in medicinal plants study. China J Chinese Materia Medica 32(5): 374-376.

57. Karaki GN, Othman Y (2009) Soilless cultivation of some medicinal and aromatic herb plants under the conditions of Arabian Gulf region. Emir J Food Agric 21(2): 64-70.
58. Huwang SJ, Kim YH, Pyo BS (2004) Optimization of Aconitine production in suspension cell cultures of Aconitum napellus L. Korean J Med Crop Sci 12(5): 366-371.

59. Giri A, Banerjee S, Ahuja P, Giri C (1997) Production of hairy roots in Aconitum heterophyllum Wall: using Agrobacterium rhizogenes. In vitro cell Devl Biol Plant 33(4): 280-284.

60. Giri A, Ravindra ST, Dhingra V, Narasu ML (2001) Influence of different strain of Agrobacterium rhizogene on induction of hairy roots and Artemisin production in Artemisia annua. Curr Sci 81: 378.

61. Sudha CG, Reddy BO, Ravishankar GA, Seeni S (2003) Production of ajmalicine and ajmaline in hairy root cultures of Rauvolfia micrantha Hook f., a rare and endemic medicinal plant. Biotechnol Lett 25(8): 631636.

62. Boliver MF, Condori J, Rimando AM, Hubstenberger J, Shelton K, et al. (2007) Production and secretion of resveratrol in hairy root cultures of peanut, Phytochemistry 68(14): 1992-2003.

63. Lan X, Quari H (2010) Hairy root culture of Przewalskia tangutica for enhanced production of pharmaceutical tropane alkaloids. Journal of Med Plant Res 4(14): 1477-1481.

64. Genschik P, Criqui MC, Parmentier Y, Marbach J, Durr $A$, et al. (1992) Isolation and characterization of a cDNA encoding a 3-hydroxy-3-methylglutaryl coenzyme A reductase from Nicotiana sylvestris. Plant Mol Biol 20(2): 337-341.

65. Maldonado IE, Vincent RM, Nessler C (1997) Molecular characterization of three differentially expressed members of the Camptotheca acuminata 3hydroxy-3-methylglutaryl CoA reductase (HMGR) gene family. Plant Mol Biol 34(5): 781-790.

66. Croxen R, Goosey MW, Keon JPR, Hargreaves JA (1994) Isolation of an Ustilago maydis gene encoding 3-hydroxy-3 methylglutaryl-coenzyme A reductase and expression of a C-terminal truncated form in Escherichia coli. Microbiology 140(9): 2263-2270.

67. Loguercio L, Scott HC, Trolinder NL, Wilkins TA (1999) HMG-coA reductase gene family in cotton (Gossypium hirsutum L.) Unique structural features and differential expression of hmg2 potentially associated with synthesis of specific isoprenoids in 


\section{Genomics \& Gene Therapy International Journal}

developing embryos. Plant Cell Physiol 40(7): 750761.

68. Jain AK, Rebecca K, Vincent M, Nessler C (2000) Molecular characterization of a hydroxymethylglutaryl-CoA reductase gene from mulberry (Morus alba L.). Plant Mol Biol 42(4): 559569.

69. Liao Z, Tan Q, Chai Y, Kaijing Z, Chen M, et al. (2004) Cloning and characterization of the gene encoding HMG-CoA reductase from Taxus medica and its functional identification in yeast. Functional Plant Biology 31(1): 73-81.

70. Jiang J, Kai G, Cao X, Chen F, He D, et al. (2006) Molecular cloning of a HMG-CoA reductase gene from Eucommia ulmoides Oliver. Biosci Rep 26(2): 171181.

71. Shen G, Pang Y, Wu W, Liao Z, Zhao L, et al. (2006) Cloning and characterization of a root-specific expressing gene encoding 3-hydroxy-3methylglutaryl coenzyme A reductase from Ginkgo biloba. Mol Biol Rep 33(2): 117-127.

72. Wang Y, Guo B, Zhang F, Yao H, Miao Z, et al. (2007) Molecular cloning and functional analysis of the gene encoding 3-hydroxy-3-methylglutaryl Coenzyme A reductase from Hazel( Corylus avellanaL. Gasaway). J Biochem and Mol Biol 40(6): 861-869.

73. Jose S, Girija D, Beena P (2008) Cloning and characterization of gene encoding HMG CoA reductase from black night shade (Solanum nigrum L.). Ind J Biotechnol 7: 66-72.

74. Liao P, Zhou W, Zhang L, Wang J, Yan X, et al. (2009) Molecular cloning, characterization and expression analysis of a new gene encoding 3-hydroxy-3methylglutaryl coenzyme A reductase from Salvia miltiorrhiza. Acta Physiol Plant 31(3): 565-572.

75. Lin J, Jin Y, Zhou M, Zhou X, Wang J (2009) Molecular cloning, characterization and functional analysis of a 3-hydroxy-3-methylglutaryl coenzyme A reductase gene from Jatropha curcas. Afri J of Biotechnol 8: 3455 .

76. Cao XY, Li CG, Miao Q, Zheng ZJ, Jiang JH (2011) Molecular cloning and expression analysis of a leaf specific expressing 3-hydroxy-3methylglutarylCoA(HMG-CoA) reductase gene from Michelia chapensis Dandy. Journal of Med Plant Res 5(16): 3868-3875.

77. Cao X, Zong Z, Ju X, Sun Y, Dai C, et al. (2010) Molecular cloning, characterization and function analysis of the gene encoding HMG-CoA reductase from Euphorbia pekinensis Rupr. Mol Biol Rep 37(3): 1559-1567.

78. Wu Q, Chao S, Chen S (2012) Identification and expression analysis of a 3-hydroxy-3methylglutaryl coenzyme A reductase gene from American ginseng. Plant Omics Journal 5(4): 414-420.

79. Abdin MZ, Kiran U, Aquil S (2012) Molecular cloning and structural characterization of HMG CoA reductase gene from Cataranthus roseus (L.) C. Donn . cv. Albus. Ind J Biotechnol 11: 16-20.

80. Deenen NV, Bachmann AL, Schmidt T, Schaller H, Sand J, et al. (2012) Molecular cloning of mevalonate pathway genes from Taraxacum brevicorniculatum and functional characterization of the key enzyme 3hydroxy-3-methylglutaryl-coenzyme A reductase. Mol Biol Rep 39(4): 4337-4349.

81. Paulet LC, Ahumada I, Cunillera N, Rodriguez Concepcion M, Ferrer A, et al. (2002) Expression and Molecular Analysis of the Arabidopsis DXR Gene Encoding 1-Deoxy-D- Xylulose 5-Phosphate Reductoisomerase, the First Committed Enzyme of the 2-C-Methyl-D-Erythritol 4-Phosphate Pathway. Plant Physiol 129(4): 1581-1591.

82. Gong YF, Liao ZH, Guo BH, Sun XF, Tang K (2006) Molecular cloning and expression profile analysis of Ginkgo biloba DXS gene encoding 1-deoxy-D-xylulose 5-phosphate synthase, the first committed enzyme of the 2-C-methyl-D-erythritol 4-phosphate pathway. Planta Med 72(4): 329-335.

83. Zhang M, Li EK, Zhang C, Gai J, Yu D (2009) Identification and characterization of class 1 DXS gene encoding 1-deoxy-D-xylulose-5-phosphate synthase, the first committed enzyme of the MEP pathway from soybean. Mol Biol Rep 36(5): 879-887.

84. Cordoba E, Salmi M, Leon P (2009) Unravelling the regulatory mechanisms that modulate the MEP pathway in higher plants. Journal of Exp Botany 60(10): 2933-2943.

85. Wu SJ, Shi M, Wu JY (2009) Cloning and characterization of the 1-deoxy-D-xylulose 5- 


\section{Genomics \& Gene Therapy International Journal}

phosphate reductoisomerase gene for diterpenoid tanshinone biosynthesis in Salvia miltiorrhiza (Chinese sage) hairy roots. Biotechnol Appl Biochem 52(1): 89-95.

86. Yang J, Adhikari MN, Liu H, He G, Zhan R, et al. (2012) Characterization and functional analysis of the genes encoding 1-deoxy-D-xylulose-5-phosphate reductoisomerase and 1-deoxy-D- xylulose-5phosphate synthase, two enzymes in the MEP pathway, from Amomum villosum Lour. Mol Biol Rep 39(8): 8287-8296.

87. Alam P, Abdin MZ (2011) Over-expression of HMGCoA reductase and amorpha-4,11-diene synthase genes in Artemisia annua L. and its influence on artemisinin content. Plant Cell Rep 30(10): 19191928.

88. Wang Y, Jing F, Yu S, Chen Y, Wang T, et al. (2011) Cooverexpression of the HMGR and FPS genes enhances artemisinin content in Artemisia annua L. J Med Plants Res 5(15): 3396-3403.

89. Singh RS, Gara RK, Bhardwaj PK, Kaachra A, Malik S, et al. (2010) Expression of 3-hydroxy-3methylglutaryl-CoA reductase, $\mathrm{p}$-hydroxybenzoate-mgeranyltransferase and genes of phenylpropanoid pathway exhibits positive correlation with shikonins content in Arnebia [Arnebia euchroma (Royle) Johnston]. BMC Molecular Biology 11: 88. 